\title{
TeACHING AND Assessing Lifelong LeARNING IN LABORATORY COURSES
}

\author{
Salim Ahmed \\ Memorial University, St. John's, NL Canada \\ Corresponding Author: sahmed@mun.ca
}

\begin{abstract}
Lifelong learning might be one of the most important attributes for students pursuing a professional degree, e.g. medicine, law or engineering. From teaching and assessment point of view, it may be one of the most challenging attributes. In engineering programs, it is one of the required graduate attributes identified by the Canadian Engineering Accreditation Board (CEAB), the Accreditation Board for Engineering and Technology $(A B E T)$ in the USA and other accreditation bodies around the world. In this article we present a laboratory procedure to teach and assess lifelong learning in an engineering program. The concept of lifelong learning as defined by different accreditation bodies is discussed first and corresponding learning outcomes are developed using the revised Bloom's taxonomy. Student activities required to achieve the outcomes are then devised. The links between pre-, in- and post-lab activities and the learning outcomes are established and the approach to run a laboratory course is designed. Finally, the assessment is planned using the so-called VALUE rubric by mapping the learning outcomes on the six dimensions of the rubric. The procedure is being implemented phase by phase in the laboratory component of a senior level course on process dynamics and control in the process engineering program at Memorial University of Newfoundland.
\end{abstract}

Keywords: Lifelong learning, Laboratory, Graduate attributes, Assessment, Learning Outcome.

\section{INTRODUCTION}

The importance of laboratory in an engineering program is well recognized. However, establishing and operating laboratories are resource intensive. Along with huge space requirements, laboratory courses require large instructional teams and continuous technical supports. Additional resources are required to maintain and ensure safe operation of equipment. From the students' perspective, significant amount of time is required to perform experiments and produce reports. Nevertheless, if a laboratory exercise is poorly designed, students do not find it intellectually challenging [1] and may even loss interest in the discipline. On the other hand, a properly designed activity may provide a feel about real life engineering works and enhance learning of complex concepts [2]. More importantly, most, if not all, of the attributes required for an engineering graduate can be developed through properly designed laboratory courses [3].

Students often come to the laboratory ill-prepared to perform and benefit from experimental activities. On the other hand, instructors tend to relegate the laboratory components of courses to teaching assistants and lab technicians. Although there have been significant work on the reform of higher education, in general, and on teaching engineering $[4,5]$, in particular, there has not been much development on reforming laboratory courses. Some recent dissemination of research e.g. for experiential learning [6] and for teaching complex concepts [2] have been reported; however, the guiding principles for laboratory reform are yet to be established.

Enhancement of graduate attributes is in the focus for curriculum reform; also this is the cornerstone of accreditation. Design of laboratory procedure to enhance specific attributes has been reported in the literature e.g. for teamwork [7], design [3] and investigation [8] attribute. It has been argued that by proper design, most of the twelve graduate attributes identified by the Canadian Engineering Accreditation Board (CEAB) can be enhanced in laboratory courses [3].

Teaching and assessment of the lifelong learning (LLL) attribute has been reported in the literature, e.g. see [9]; however, mainly in the design based courses. Laboratory courses set a proper environment for contextbased learning to enhance graduate attributes, especially LLL. In this work, a model to design laboratory procedure to teach and assess lifelong learning is presented. First, an analysis of the attribute from conceptual and accreditation point of view is presented along with highlights of its importance in section 2. Assessment aspects of the attribute are presented in section 3 followed by design of a specific course to implement the presented model in section 4. Finally, some concluding remarks are drawn in section 5 . 


\section{LIFELONG LEARNING}

\subsection{The concept of lifelong learning}

In an institutional setting, learning takes place within an infrastructure containing professional instructors, structured courses and formal assessments. The concept of lifelong learning is to learn beyond the institutional infrastructure and in the absence of instruction and assessment [10]. In other words, it is a deliberate as well as continuous activity for self-education beyond the limits of formal schooling [11]. However, the skills and competence required for self-education can be efficiently developed through formal education. In fact it is one of the most important purposes of higher education to transform students into lifelong learners through development of the required skill set. University and college education should provide the foundation to enable students to continue to learn in work, social and community settings.

\subsection{Significance of lifelong learning}

Lifelong learning is crucial for knowledge-based economy and society. European universities' charter on lifelong learning emphasizes that "attention to issues of lifelong learning in quality assurance process is therefore a necessity to ensure that lifelong learning is recognized as a national priority" [12]. Specific to engineering, the half-life of knowledge is between two and eight years [13]; this highlights the need for continuing education and learning. The Canadian Academy of Engineers (CAE) highlights lifelong learning as an "urgent imperative" for ensuring public safety, sustainability of environment, competitiveness of national economy, respect of the profession, profitability of employer and career fulfilment [14]. CAE suggests establishing lifelong learning programs for engineers as a major institutional mission and include the extent of commitment to lifelong learning in internal and external departmental reviews and accreditation procedures [15]. CAE promotes that "the mind-set that the initial degree is only the first step in the pursuit of engineering competency" [14].

\subsection{Lifelong learning as a graduate attribute}

Life-long learning is one of the twelve attributes that the graduate of a program must possess for the corresponding program to be accredited by the CEAB. According to $\mathrm{CEAB}$, the lifelong learning attribute for graduates is defined as "an ability to identify and to address their own educational needs in a changing world in ways sufficient to maintain their competence and to allow them to contribute to the advancement of knowledge” [16]. Regarding all the graduate attributes,
CEAB documentation adds "It is recognized that graduates will continue to build on the foundations that their engineering education has provided". The above statement highlights the special place of lifelong learning within the set of graduate attributes and implies that the graduates will be lifelong learners with regards to all the attributes.

In the US, the Accreditation Board for Engineering and Technology (ABET) requires that engineering graduates should have "a recognition of the need for, and an ability to engage in lifelong learning" [17].

The Quality Assurance Agency for Higher Education (QAA) in the UK requires that holders of a Bachelor's degree will be able to "identify and address their own learning needs, including being able to draw on a range of current research, development and professional materials" [18].

The above attributes (outcomes) show that there are two distinct abilities associated with lifelong learning; (i) ability to recognize and identify the need for selfeducation and (ii) an ability to address the identified needs; in the following discussions these two abilities will be referred to as A1 and A2, respectively. As discussed in the following section these two abilities falls onto two domains in the learning taxonomy; the implication is that different techniques are required for their assessment.

\subsection{LLL abilities and taxonomy for learning}

The above abilities are linked to metacognition. In the revised Bloom's taxonomy, two aspects of metacognition have been distinguished; (1) knowledge about cognition and (2) control, monitoring, and regulation of cognitive process [19]. These two aspects can be linked to concepts of self-knowledge and self-regulation. A link of ability (i) and aspect 1 is clear from their respective definitions; the same is true for ability (ii) and aspect 2 .

In the revised taxonomy table, metacognitive knowledge is added as the fourth category in the knowledge dimension. The other types of knowledge in the knowledge dimension, namely, factual, conceptual and procedural knowledge pertain to subject matter content while metacognitive knowledge is knowledge of cognition and about oneself in relation to various subject matters [19]. On the other hand, metacognitive control involves processes in the cognitive process dimension namely, remember, understand, apply, analyze, evaluate and create.

A special feature of the outcomes related to metacognitive knowledge and thus to ability (i) is that there is no unique correct answers. Such knowledge should be assessed with regards to context of activities. The objective of teaching and assessing LLL is to make students aware of their own learning and facilitate student engagement in meta-cognitive processes by providing a reflective point of reference [20]. 


\section{ASSESSMENT OF LIFELONG LEARNING}

In higher education assessment serves two purposes: (i) to provide feedback to student on learning and (ii) to certify success of students. In this context, once the required competence and skills related to a particular attribute is defined, summative and formative assessment can be conducted. However, for the lifelong learning attribute there is a subtle distinction; it requires that the students play an active role in the assessment process. As commented in [20] "lifelong learning traits are virtually impossible to observe through conventional summative assessment methods, necessitating self-evaluation as a key part of any evaluation process”. Also it is important to recognize that the purpose is to assess preparation for lifelong learning and not to measure continuing learning among alumni through some longitudinal measures.

\subsection{Criteria for assessment}

For the purpose of assessment, Ability A1- “ability to recognize and identify the need for self-education” can be further segmented as:

A1a: Ability to identify concepts and skills required to complete an assigned task

A1b: Ability to identify own knowledge and that of team members with respect to a given assignment; and

A1c: Ability to identify knowledge gaps and skill development required to complete a task meeting all the requirements.

Similarly A2- "an ability to address the identified needs" can be divided into:

A2a: Ability to identify resources and mentors for a given body of knowledge;

A2b: Ability to identify own learning strategies and preferences with respective advantages and disadvantages and to develop strategies and plan activities to acquire required knowledge

A2c: Ability to monitor and evaluate individual and team learning and to decide when learning is sufficient

A2d: Ability to reflect on own learning to identify and resolve issues to address any deficiency

It is understandable that all the above components are not required to address in one course; neither it is feasible. We will address a number of the above abilities as defined by the following learning outcomes.

\subsection{Learning outcomes}

For the course and the approach under consideration, the following learning outcomes (LO) were found to be suitable for assessment.

LO1: Summarize activities and list the concepts required to perform an experiment and obtain desired results (A1a).
LO2: Retrieve already known relevant knowledge and concepts (A1b).

LO3: Identify own knowledge gaps and that of the team members (A1c).

LO4: Identify and distinguish resources required to acquire an identified body of knowledge and list of concepts (A2a).

LO5: Select team members based on individual strengths, plan activities to acquire knowledge and concepts and implement developed plan (A2b).

LO6: Monitor and evaluate individual and team learning (A2c).

LO7: Critique own learning and that of team members, analyze deficiencies and hypothesize strategies to address issues (A2d).

A discussion on the minimum level of mastery students must possess when they graduate to develop as lifelong learners was presented in [9] based on the Bloom's Taxonomy. In the context of the revised Bloom's Taxonomy discussed in Sec 2.3, the above LOs are mapped on the taxonomy table and presented below.

Table: Learning outcomes mapped on the taxonomy table.

\begin{tabular}{|l|l|l|l|}
\hline \multirow{2}{*}{$\begin{array}{l}\text { The knowledge } \\
\text { dimension/ }\end{array}$} & \multicolumn{3}{|c|}{ Metacognitive knowledge } \\
\cline { 2 - 4 } $\begin{array}{l}\text { Cognitive process } \\
\text { dimension }\end{array}$ & $\begin{array}{l}\text { Strategic } \\
\text { knowledge }\end{array}$ & $\begin{array}{l}\text { Knowledg } \\
\text { e about } \\
\text { cognitive } \\
\text { task }\end{array}$ & $\begin{array}{l}\text { Self } \\
\text { knowledg } \\
\text { e }\end{array}$ \\
\hline $\begin{array}{l}\text { Remember } \\
\text { (Recall) }\end{array}$ & & & LO2 \\
\hline $\begin{array}{l}\text { Understand } \\
\text { (Summarize) }\end{array}$ & LO1 & LO5 & \\
\hline $\begin{array}{l}\text { Apply } \\
\text { (Implement) }\end{array}$ & LO4 & & $\begin{array}{l}\text { LO3, } \\
\text { Analyze } \\
\text { (Organize, } \\
\text { Differentiate) }\end{array}$ \\
\hline $\begin{array}{l}\text { Evaluate (Check, } \\
\text { Critique) }\end{array}$ & & LO5 & $\begin{array}{l}\text { LO6, } \\
\text { LO7 }\end{array}$ \\
\hline $\begin{array}{l}\text { Create (Generate, } \\
\text { Plan) }\end{array}$ & LO7 & LO7 & LO5 \\
\hline
\end{tabular}

\subsection{Instructional components}

Assessment of a particular graduate attribute is just one aspect; development of the same is of greater importance. Instructional components of a course should contain elements geared to particular attributes. For lifelong learning students need to be instructed on learning styles, self and peer assessment, determining authenticity of documents pertaining to the specific field, professional bodies worthy of affiliation and so on. 


\section{LABORATORY COURSE DESIGN}

The laboratory courses are appropriate for assessing lifelong learning as (i) experiments offer a real-life problem, (ii) laboratory works create a well-defined context based learning environment, (iii) a high degree of teamwork is involved in the laboratory courses, (iv) students need to apply concepts in a new environment and so on. When a laboratory components is part of a course, students may have to perform experiments before the relevant topic is covered in lecture. This is often an issue raised by students. However, an effective lifelong learning environment can be created by taking advantage of the problem. Another important aspect of lab courses is that experiments are done throughout the term with intervals in between for the students to reflect on their learning and modify their learning strategies and implement modified strategy in the following sessions. Thus LLL becomes an ongoing activity throughout the term which is one of its important aspects.

All the above mentioned learning outcomes can be achieved and assessed in a laboratory course; however, it is not necessary to cover all outcomes in one course. In this section, design of a senior level course is outlined to describe how, through pre-, in- and post-lab activities, the entire list of outcomes can be addressed.

\subsection{Course information}

The course designed to emphasize on LLL is a senior level course titled "Process Dynamics and Control" offered to undergraduate students in term 7 of the process engineering program at Memorial University of Newfoundland. This is a typical course on process control offered in most chemical and process engineering programs throughout the world. The two broad topics covered in this course are dynamic modeling of simple processes and design and implementation of controllers.

Assessment items in this course include a laboratory component along with a term project, midterm and final examinations, assignments and quizzes.

\subsection{Laboratory experiments}

Two laboratory scale experimental set-ups are used in the course. A level control system and a temperature control system. Each team performs open loop test on each system for system identification. Identified models are then used for controller design. In the second set of experiments, each team implements the designed controllers to the systems and assesses performance of the designed controller. Thus each team conducts four laboratory experiments.

For the system identification exercises, students perform a series of step tests. The idea behind doing multiple tests is to observe variations in the process dynamics with changing operating conditions. Also they need to use two different methods to find model from step tests. During the controller implementation process, students need to use two sets of controllers obtained using two different methods. The idea is to demonstrate that the controller design approaches are not universal, and depending on system characteristics, proper choice and criteria should be made.

\subsection{Activities to address LLL}

Students are involved in a series of pre- and post-lab activities along with the in-lab performance. The lab is performed in the so-called unstructured way [3] where students are not provided with any procedure to follow; instead each team needs to design their own procedures as part of pre-lab activities. When students follow a set of prescribed instructions, the laboratory activities become more mechanical and students often do not analyze why they are doing what they are doing [22]. In an introduction session, the operations of the processes are demonstrated and students are provided with the equipment manuals. Following the demonstration and using the manuals, each team is required to outline the step by step procedure needed to obtain the desired sets of data to meet laboratory objectives. System identification exercises in a laboratory environment are quite simple. However, when provided with a procedure to follow, students often just follow the steps without having an understanding of the functionalities of equipment. By developing the procedure, students realize the need for each step.

In order to enhance LLL skills, students are required to identify models from step response using a method that is not covered in the course and not included in the textbook. Also for controller design, along with the prescribed one, an alternative method, not discussed in the textbook, is to be used.

As a pre-lab activity each team required to prepare and submit the experimental procedure (LO1). In addition a list of key concepts to perform the experiment and get the desired results is required, preferably in a tabular form (LO1). The table should also contain knowledge of individual members regarding the concepts (LO2) and indicate whether the concept is to be learned (LO3). Sources to learn the unknown concepts should be identified and tabulated (LO4) and team members responsible to learn the concepts should be listed in the table with time-frame to complete the task (LO5). During the first half hour of the laboratory session, the team will meet with the instructional team to evaluate their learning (LO6) and critique team performance regarding the learning exercise (LO7). Deficiencies in learning should be identified and the team should hypothesize remedy for the deficiencies and overcome problems (LO7). 
Evaluation of learning, identification of deficiencies and prescribed remedies should also be tabulated.

Note that there are two similar lab sessions for the identification experiments. The sessions are different only in terms of the set-up. Because the two processes are different, the step by step procedures will be different; however, conceptually the labs are similar. This gives students an opportunity to revisit their learning. Unknown concepts identified in the first sessions are known for the second session. Moreover, by the time students go for the second session, more topics will be covered during lecture and the students are expected to have a better understanding of different concepts. This will give an opportunity to reflect on self-learning. The same is applicable for the two sessions for controller implementation.

\subsection{Deliverables to assess LLL}

For each lab session, individual teams require to submit a pre-lab and a post-lab report. The pre-lab report contains the operational procedure and table of concept inventory and learning plan along with evaluation of learning. The post-lab report contains details about data generation, calculations and results. To encourage selfassessment, teams are allowed to re-submit the pre-lab report along with pots-lab report by highlighting the changes. This will allow students to incorporate insights about the experiments gained during the experiment.

The item most relevant to LLL assessment is the prelab report and the part of the post-lab report that discusses about the alternative methods for systems identification and controller design. The post-lab report should identify the sources and applicability of the alternative methods and provide reasons for choosing.

\subsection{Rubrics for assessment}

In the literature there are various rubrics and tools developed for assessing different aspects of lifelong learning. Detailed discussions on different tools can be found in [21] and the references therein. In this course, we adopt the so-called VALUE rubric developed by the Association of American Colleges \& Universities (AAC\&U). Note that the equivalent of the graduate attribute lifelong learning is defined by ABET as the learning outcome "Foundations and Skills for Lifelong Learning”. The VALUE rubric assesses the outcome using six dimensions [22]. We plan to use the VALUE rubric by mapping the above mentioned learning outcomes on the six dimensions as follows: curiosity-LO3 and LO4, initiative-LO1 and LO2, independence-LO6, transfer-LO5 and reflection-LO7. Alternatively, the LLL dimensions outlined in [20] along with its mapping on the VALUE dimension, can be used.

\subsection{Feedback to students}

As mentioned earlier, feedback is one of the uses of assessment. To enhance LLL, it is tantamount that regular feedback on learning be provided in a timely manner. During meeting with each team, the instructional team will take note of the discussions and evaluate team learning and identify shortcomings in the learning approach. Based on the findings, written feedback is provided to each team. Also examples of well performing teams will be shared. Students will be made aware that the feedback should be acted upon. During the meeting for the second and fourth lab sessions, it will be discussed how the feedbacks from first and third pre-lab reports were implemented.

\subsection{Students’ feedback}

Feedback should always be a two way communication and students should have the opportunity to provide feedback. During the meeting with individual teams, students' comments on the advantages and disadvantages of the approach to conduct lab will be discussed. Ways to address issues and concerns will be discussed and implemented. Also students will be requested to provide feedback as part of course evaluation questionnaire.

\subsection{Implementation issues}

Students are familiar with post-lab activities; however, pre-lab activities are typically less intensive. In the proposed approach pre-lab activities are most significant for assessment of lifelong learning; also it amounts to significant workloads. To compensate for the additional workloads, in homework assignments questions based on experimental set-ups are included. More importantly, students are made aware of the motivations and usefulness of each activity that they are required to perform.

Formative assessment is seen as the prescribed form of assessment for LLL and the use is to provide feedback. However, when an item is used only for feedback and not graded, it is not considered as a priority item by the students. Hence, we suggest grading the concept table, the item to assess LLL as part of the lab report. Nonetheless, providing feedback remains as the focus of the activities.

\subsection{Other aspects}

This article, and articles in general on the assessment topic, addresses graduate attributes one at a time. Although, for the purpose of analysis and documentation for accreditation, it may be suitable, considering attributes in isolation may not be the most effective way for developing the attributes. For example, certain aspects of 
lifelong learning are well knitted with teamwork. Selfassessment within the context of a team is better suited. Similarly, while assessing teamwork skills, contributions of individual members are largely dependent on their selfeducation and communication skills. To ensure effective development of graduate attributes, it is important that activities are developed in a way that addresses attributes as a set and not in isolation.

\section{CONCLUDING REMARKS}

The importance of lifelong learning in engineering career as well as in engineering education has been well recognized. Guidelines for professional and academic institutions for ensuring lifelong learning have been suggested by engineering associations. Program and course design to develop and assess the LLL attribute have also been published in the literature. However, there has not been any significant development on how to conduct the laboratory courses in engineering programs to develop this important attribute. We suggest a mechanism to conduct a laboratory course to develop and assess LLL. Although the approach has been developed for a particular course, it can be generalized for other laboratory courses in other disciplines and to some extent to theory courses as well. This approach is in the preliminary phase of implementation. A study on the effect of the proposed approach in developing the attribute compared to the traditional way of conducting laboratory is currently undergoing and the results will be shared in the future. Also the proposed mechanism will be scrutinized in the future for possible enhancement based on students' feedback to effectively address a set of relevant graduate attribute in contrast with addressing attributes in isolation.

\section{References}

[1] G. Norval, P. Szabo, G. Wilson, P. Jowlabar, "A new approach to the unit operations laboratory at the University of Toronto”. Proc. 2011 CEEA Conf., St. John's, NL, June 2011.

[1] Karl Johansson, Alexander Horch, Olle Wijk, and Anders Hansson,"Teaching multivariate control using the quadruple-tank process,” Proc. 38th Conf. on Decision and Control, Phoenix, AZ, USA, December 1999.

[3] Salim Ahmed, Syed Imtiaz, Lesley James, and Darlene Spracklin-Reid, "Designing laboratory procedures to enhance graduate attributes”, CEEA 2013, June 2013, Montreal, QC, Canada.

[4] Richard M. Felder, Donald R. Woods, James E. Stice, Armando Rugarcia, "The future of engineering education ii. Teaching methods that work”, Chem. Engr. Ed, 34(1), 2639 (2000).

[5] Phillip C. Wankat and Frank S. Oreovicz, Teaching Engineering, McGraw-Hill, Inc., 1993.
[6] Mahmoud Abdulwahed, and Zoltan Nagy, “Applying Kolb's experiential learning cycle for laboratory courses” $J$. Engr. Education, July 2009, 283-294.

[7] Clemence Fauteux-Lefebvre, Denis Gravelle and Nicolas Abatzoglou, "In-depth learning and development of experimental and team work skills in laboratory courses," CEEA 2013, June, 2013, Montreal, QC, Canada.

[8] Salim Ahmed, Yan Zhang and Darlene Spracklin-Reid, “An expert follower approach to enhance graduate attributes in laboratory courses”, CEEA 2015, May 31-Jun 3, Hamilton, ON, Canada.

[9] Nikos J. Mourtos, "Defining, teaching and assessing lifelong learning skills", 33rd ASEE/IEEE Frontiers in Education Conference, Nov 5-8, 2003, Boulder, CO, US.

[10] David Boud and Nancy Falchikov,“Aligning assessment with long-term learning”, Assessment and Evaluation in Higher Education, 31(4), August 2006, pp. 399-413.

[11] P. Candy, "Self-Direction for Lifelong Learning: A Comprehensive Guide to Theory and Practice”, Jossey-Bass, San Franciso, 1991.

[12] European university Association, "European Universities' charter on lifelong learning”, Brussels, Belgium, July 2008.

[13] Wm. A. Wulf and George M. C. Fisher, "A makeover for engineering education”, Issues in Science and Technology, Vol. XVIII, Issue 3, Spring 2002.

[14] CAE, "Lifelong Learning for Professional Engineers", 1997

[15] C.W. Bowman, "Lifelong Learning for Professional Engineers”, Engineering Issues, No.6, September 1997.

[16] Canadian Engineering Accreditation Board., 50th Accreditation Criteria and Procedures, 2015.

[17] Larry J. Shuman, Mary Besterfield-Sacre, Jack McGourty, "The ABET professional skills - Can they be taught? Can they be assessed?” J. Engr. Education, Jan 2005, 41-55.

[18] QAA, “Subject Benchmark Statement” February 2015.

[19] Anderson, Lorin W., and David R. Krathwohl. A Taxonomy for Learning, Teaching, and Assessing: A Revision of Bloom's Taxonomy of Educational Objectives. New York: Longman, 2001.

[20] N. Simper, J. Kaupp, B. Frank and J. Scott. “Development of transferable learning orientations tool: providing metacognitive opportunities and meaningful feedback for students and instructors", Assessment \& Evaluations in Higher Education, 41(8), 2016, 1159-1175

[21] Richard M. Felder, Steven W. Peretti, “A Learning theorybased approach to the undergraduate engineering laboratory”, 1998 ASEE Annual Conference, Seattle, June 28 - July 1, 1998

[22] AAC\&U., "Foundations and skills for lifelong learning VALUE rubric" retrieved on May 1, 2017 from www.aacu.org/sites/default/files/files/VALUE/LifelongLear ning.pdf 